\title{
SOCIAL NETWORKS, AWARENESS AND BEHAVIORAL MODIFICATION TO REDUCE AIR POLLUTION AND CARBON FOOTPRINTS: THE CLAIRCITY PROJECT IN THE LIGURIA REGION OF ITALY
}

\author{
CARLO TROZZI, RITA VACCARO \& MARTINA TROZZI \\ Techne Consulting srl, Italy
}

\begin{abstract}
The paper discusses the use of social media (Facebook, Twitter and Instagram) to promote the activities of the ClairCity project in Genova area and to increase awareness and induce behavioral modification to reduce air pollution and carbon footprint. The activities are implemented in the frame of Horizon 2020 Project ClairCity, a four year project (2016-2020) working directly with citizens and local authorities in six countries around Europe. From the adoption of the Kyoto Protocol to the United Nations Framework Convention on Climate Change, great attention has been devoted to reducing carbon dioxide and other greenhouse gases emissions at the international level and specific initiatives at city level have been launched. At the same time despite continued efforts to reduce emissions of harmful air pollutants, air pollution remains a worldwide concern, including in large areas of Europe, particularly in cities where the effects on human health are the major concerns. The project start from the consideration that city citizens' behaviour and day-to-day activities are crucial element to modify to achieve the goal of reducing air pollution. To promote ClairCity across a broad range of residents in each partner city and beyond, a suite of social media tools are running. Particular attention is devoted to the use of local Facebook groups to disseminate the information. Analytic instruments are used to evaluate the penetration of the information between the local population while results on direct participation of citizens to surveys and meetings are used to evaluate the follow up of the social media actions. The conclusion is that, while a traditional use of social networks is useful to spread the results of the project between the scientific community and the technicians involved in the work, the population is hardly made aware. To increase awareness, it is necessary to bring communication where the population is most easily reachable. To this end, an activity aimed at Facebook groups that are of local interest and are directly managed by citizens is an important tool for spreading project ideas and involving non-professional people.
\end{abstract}

Keywords: ClairCity project, social media, air pollution, emissions, carbon footprint.

\section{INTRODUCTION}

ClairCity [1] is a four-year project (2016-2020) developed in the frame of Horizon 2020 [2] working directly with citizens and local authorities in six countries around Europe. There are sixteen partner organisations involved in the project.

Two decades of established emissions inventories and evolving modelling practices across the EU have only taken air quality management and carbon reduction strategies so far. It can be argued that this is because the policy and methodologies used have, for a number of reasons, led us towards attempts to reduce emissions predominantly through technical measures, and away from changing the way our societies and cities operate and function.

ClairCity project apportions air pollution emissions and concentrations, carbon footprints and health outcomes by city citizens' behaviour and day-to-day activities in order to make these challenges relevant to how people chose to live behave and interact within their city environment. ClairCity uses six pilot cities/regions (Amsterdam, NL; Bristol, UK; Aveiro, PT; Liguria, IT; Ljubljana, SI; and Sosnowiec, PO). 
The paper discusses the use of social network to disseminate the information and directly involve the citizens.

Particular attention is devoted to the use of local Facebook groups to disseminate the information and to the use of sponsored posts.

Analytic instruments are used to evaluate the penetration of the information between the local population while results on direct participation of citizens to surveys and meetings are used to evaluate the follow up of the social media actions.

\section{CLAIRCITY PROJECT}

ClairCity [3] apportions air pollution emissions and concentrations, carbon footprints and health outcomes by city citizens' behaviour and day-to-day activities in order to make these challenges relevant to how people chose to live and behave and interact within their city environment.

Through an innovative engagement and quantification toolkit, the project stimulates the public engagement necessary to allow citizens to define a range of future city scenarios for reducing their emissions to be used for supporting and informing the development of bespoke city policy packages out to 2050 .

Using six pilot cities/regions (Amsterdam, NL; Bristol, UK; Aveiro, PT; Liguria, IT; Ljubljana, SI; and Sosnowiec, PO), ClairCity source apportions current emissions/concentrations and carbon emissions not only by technology but by citizens' activities, behavior and practices.

ClairCity explores and evaluates current local, national and international policy and governance structures to better understand the immediate policy horizon and how that may impact on citizens and their city's future. Then, working with the new methods of source apportionment to combine both baseline citizen and policy evidence, ClairCity uses innovative engagement methods such as Games, an App and Citizen Days to inform and empower citizens to understand the current challenges and then subsequently define their own visions of their city's future based on how their want to live out to 2050 . The impact of these citizen-led future city scenarios is analysed, to develop city specific policy packages in which the clean-air, low-carbon, healthy future, as democratically defined by the city citizens, is described and quantified.

The results of the ClairCity process are evaluated to provide policy lessons at city, national and EU levels. Additionally, the toolkit structure is developed for all EU cities with more than 50,000 citizens establishing a basis to roll out the ClairCity process across Europe.

\section{CLAIRCITY SOCIAL MEDIA AND ONLINE PRESENCE}

ClairCity works across six cities in Europe to engage the public on issues of air pollution, carbon emissions and the future of their cities and regions. Core to the project are a set of innovative tools that will allow city residents to participate in understanding the problem, visioning the future and backcasting to achieve results for their city.

To promote ClairCity across a broad range of residents in each partner city and beyond, the project are running a suite of online and social media tools [4]. ClairCity has set up accounts on relevant platforms, and project partners collaborate to manage the use and development of online dissemination.

The project website is www.claircity.eu (Fig. 1); complete by October 2016, it contains Portuguese, English, Slovenian, Polish and Italian sections to incorporate visitors from our partner cities and beyond. It hosts more detailed information on our project design and information on future outputs. 

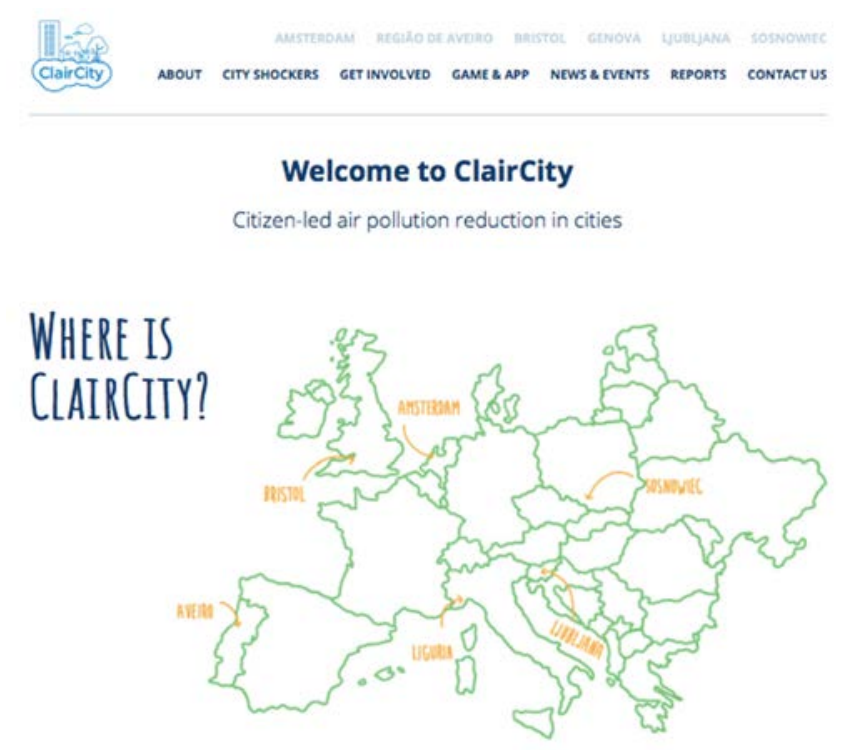

How do you want to live, work and travel in the future?

Thars the quetion we are asiong colizens across Europe. Uniquely, this project puts the poner in the hands of chizens 10 determine the best local solutions find your oity.

Figure 1: ClairCity website.
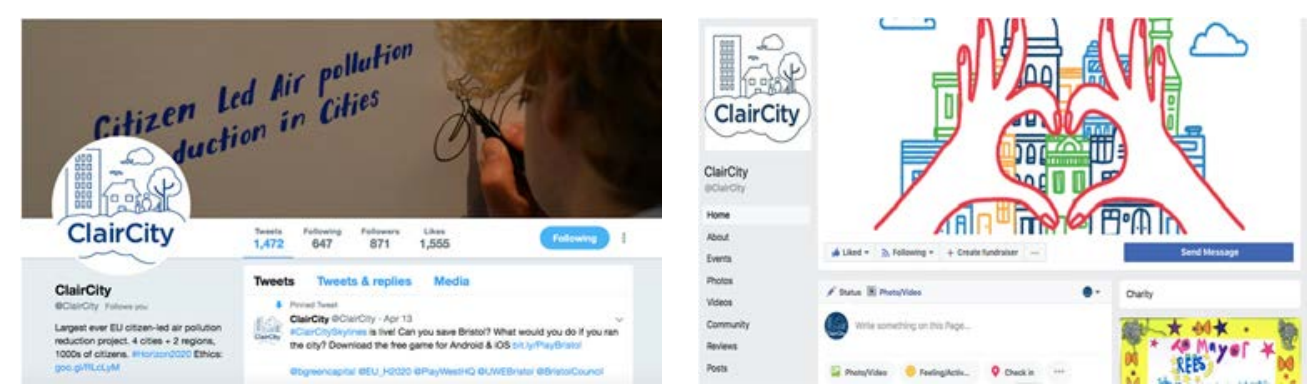

Figure 2: ClairCity Twitter and Facebook accounts.

The website links to ClairCity social media platforms on Twitter and Facebook (Fig. 2). Twitter handle is @ claircity https://twitter.com/ClairCity and the project has a publicly accessible Facebook page: https://www.facebook.com/ClairCity/. As activities are launched in multiple countries local social media accounts are opened in the different countries.

The social media accounts are used to direct people to ClairCity website content and events but are also used to highlight (through direct Tweets or Retweets) appropriate content which aligns with project Key Messages. Consortium. Videos resulting from the project are stored on YouTube and embedded into the ClairCity website. Sharing of content is encouraged using Twitter and Facebook. 


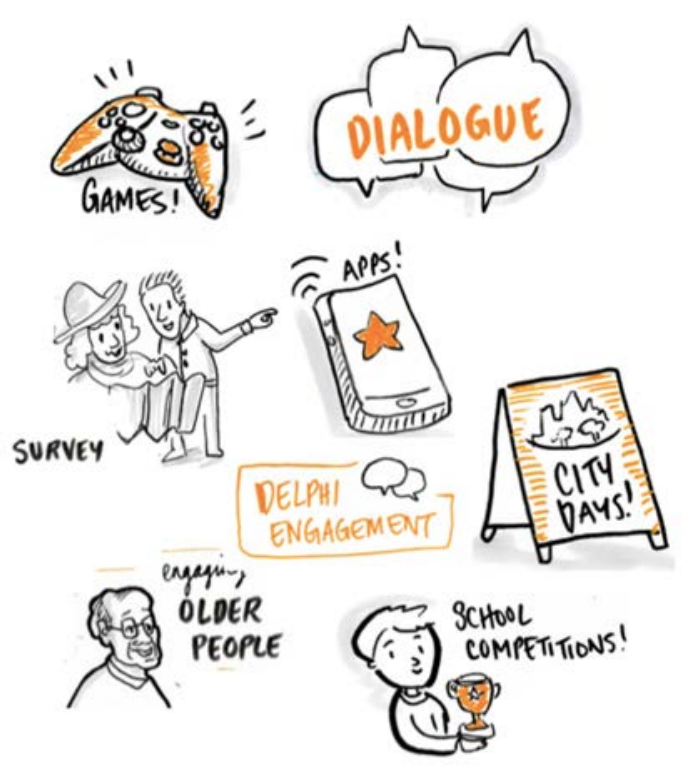

Figure 3: ClairCity engagement activity.

\section{CLAIRCITY CITIZENS AND STAKEHOLDER ENGAGEMENT}

The communication strategy introduced in the previous chapter is an important instrument to support one of the most important primary objective of the project: to engage key stakeholders across all of our partner cities from different European regions to give them the platform to generate their vision for a low carbon, clean air futures.

This goal is supported by specific task objectives that include:

- Utilization of DELPHI process to engage citizens and stakeholder and give them a platform to describe their personal future visions of their city;

- To create serious game experience to actively engage city citizens and stakeholders with an enhanced understanding of the air quality and carbon issues within cities as through games technology, ownership of the problem and exploration of a diverse range of decisions and solution pathways is possible:

o Exposure to the challenge of city air quality, carbon management and citizen health;

o An ability for stakeholders to create, visualise and share their progress to 2050;

o Utilise decision pathways to inform or generate stakeholder dialogue;

o Package data for the foundations of a Decision Support System.

- To give the user awareness of their personal exposure and possible health effects and to give a tool where the user gets an understanding of personal contribution to air quality and carbon footprint and change behaviour to reduce impacts and decrease adverse health effects;

- To empower citizens to better understand the specific challenges and opportunities that their city currently offers and engage them into moving towards improved air quality, reduced carbon footprints and decreased health risks;

- The following steps are undergoing about engagement activities: 


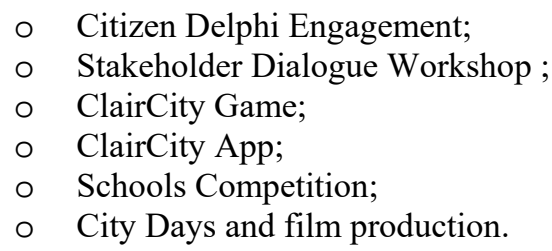

The Citizen Delphi Engagement used three rounds: a broad-spectrum public engagement (including an online questionnaire), an online-only questionnaire and a Delphi Workshop followed by the Stakeholder Dialogue Workshop.

The activities are developed in all the partner cities. In the paper a first balance of activities in the Liguria region (Genoa) is reported and discussed with focus on social media use.

\section{DELPHI PROCESS}

Delphi is a method for solving complex problems by asking for people's (usually experts') opinions. The process happens in several stages or rounds. The aim is to draw on a wide range of opinions to eventually arrive at a consensus leading to one solution, or alternatively a dissensus that leads to multiple solutions with a number of competing views.

It's different to usual consultation approaches as respondents are not presented with a preconceived idea at the outset, and it helps to ensure that everyone's opinion is included.

The Citizen Delphi Engagement used three rounds:

1. Public Engagement and Questionnaire 1 - The first round intend to determine, in broad terms, citizens' main "days to days" activities, their concerns and their views on a range of open questions. Particularly the citizens responded about what they like about their city, how they would improve over the next 35 years and successively to specific questions about their travel during the day and the home heating.

2. Questionnaire 2 - The second round asks respondents to reflect on themes arising from Round 1 through participating in an "online only" questionnaire. This round is about beginning to shape consensus/dissensus around common themes. It enables respondents to think about the themes highlighted by respondents in Round 1. In the Questionnaire 2 there are some questions on from the activity-based travel/home heating, other city specific questions from Round 1, others ask to the respondents to state whether they agree or disagree with a set of ambitious policy measures that would affect their day-to-day activities. Questions are mainly closed (multiple choice).

3. Delphi Workshop - In the third round, a representative sub-group of Round 2 participants were invited to attend the Delphi workshop. At the workshop, participants were presented with information about air quality, climate change and health. They will also be presented with the responses to the Round 2 questionnaire and asked to consider how the ambitious policy measures would affect their lives if implemented, and how their implementation could be facilitated.

\section{SOCIAL MEDIA AND CITIZEN ENGAGEMENT}

In recent years, many works have analysed the relationships between social media and citizen engagement [5], [6], also related to environmental issues [7]-[9]. Special attention was devoted to specific social group such as students [10] and more generally young people [11] 
and to the role of influential individuals [12]. Also, the relationships between self-reported and objective measures of pro-environmental behaviour were investigated [13], [14].

In Skoric and others [5] meta-analytic study, that reviews empirical research published from 2007 to 2013, the authors conclude that all statistically significant findings suggest a positive relationship between social media use and engagement and only a handful of negative, non-significant findings have been reported. The results suggest that the use of social media generally has a positive relationship with engagement and its three subcategories, that is, social capital, civic engagement, and political participation. More specifically, they find small-to-medium size positive relationships between expressive, informational, and relational uses of social media and the above indicators of citizen engagement. For identity-oriented and entertainment-oriented uses of social media, their analyses find little evidence supporting their relationship with citizen engagement.

Also of interest in the analysis of results of social media campaigns is the association between self-reported and objective pro-environmental behaviour. Kormos and Gifford [14] conclude that their meta-analysis revealed a strong association between its, but, if our ultimate goal is to help effect objective behaviour change, then we have much to gain by focusing on establishing and improving self-report validity, as well as including more objective measures, for the purposes of assessing pro-environmental behaviour. These considerations we think can be applied also to social network generated interests and effective behaviour changes engagement.

\section{LIGURIA REGION CLAIRCITY CASE STUDIES}

The social network strategy in ClairCity project follows the different stage of citizens engagement activities as described in Section 4. Social network strategy has been designed for Genova following the general indication of the project with some specificity for the local situation.

In Italy, Internet penetration rates (defined as the number of internet users per 100 people) is $62.1 \%$ following GlobalWebIndex forecasts [15].

\subsection{Starting social network platforms}

Profiles on social networks were opened in June 2017 in particular, Twitter and Facebook were used. Then, in August 2017, an Instagram profile was also started. In the following Fig. 4 for Twitter, Fig. 5 for Facebook, and Fig. 6 for Instagram the website page are reported.

The general appearance of the profiles is consistent with the graphics of the entire project, each post contains images related to the territory involved (the Liguria region and the city of Genoa), and the language of posts is always aimed at asking the opinion of citizens and the solutions they propose to the problems raised rather than providing our solutions.

\subsection{Delphi process implementation}

In order to promote the compilation of the questionnaires by citizens and the participation at the Delphi Workshop, social media (Facebook, Twitter and Instagram) were constantly used by the ClairCity team during all the period of the surveys. Also, during the interviews, the citizens were invited to enter in Facebook page of ClairCity Liguria and to look Twitter and Instagram (especially used by the young people) and the publicization through social media has much supported the diffusion of the finality of the project. 


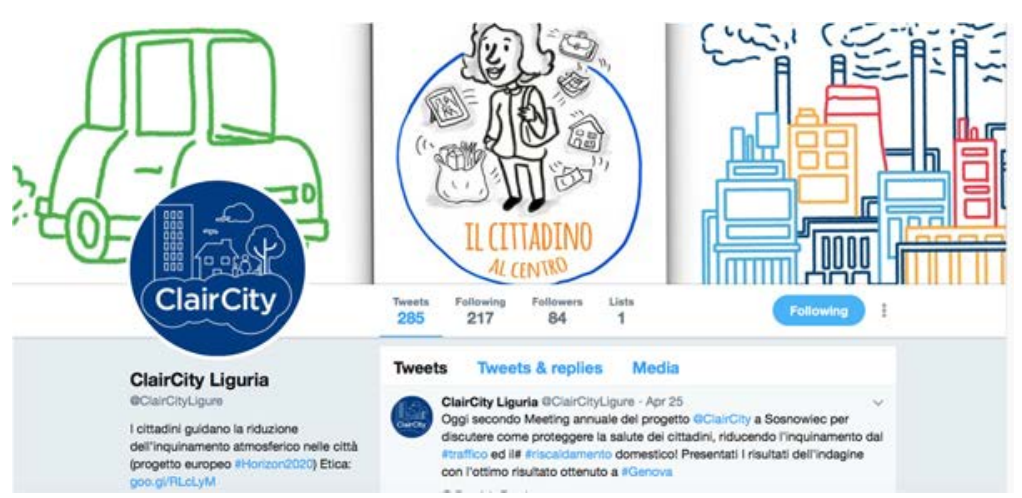

Figure 4: ClairCity Liguria Twitter page.

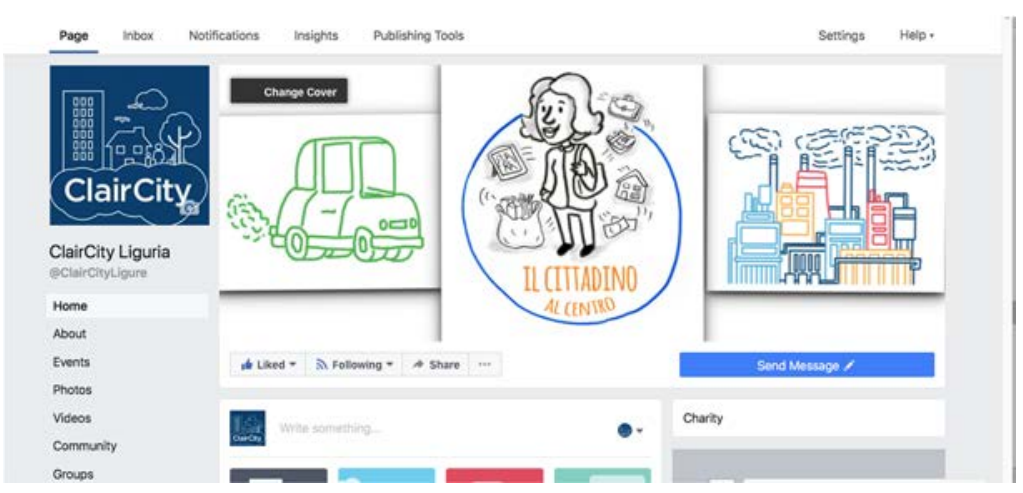

Figure 5: ClairCity Liguria Facebook page.

(2) Instagram
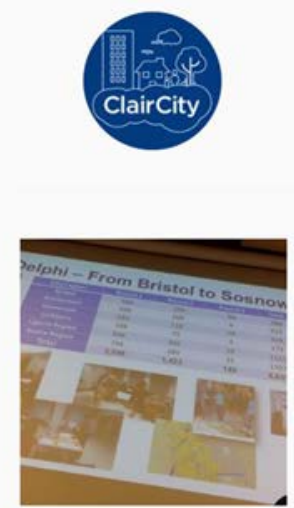

a cerca

(6) 0 옹

Figure 6: ClairCity Liguria Instagram page. 
Particularly, the diffusion of the ClairCity project and of its different phases through the social media has permitted to raise many people which then have acceded to the questionnaires available on the ClairCity website.

Furthermore, some Associations and Organizations of Genoa opportunely contacted have put on their Facebook pages the link to the survey.

That, together with the publicization on different institutional websites, direct contacts and other activities has permitted to raise a very good result:

- Round 1 Survey: 649 questionnaires (295 interviews and 354 online questionnaires)

- Round 2 Survey: 763 online questionnaires

- $\quad$ Round 3 Delphi Workshop: 19 people participated and discussed about the measures to improve air quality and reduce carbon footprint in their city.

Totally, the number of people involved in the Delphi process is 1431. That is a very good result, considering that the theme, whether important for the citizen's life, is not so funny.

Next year, following the launch and playing by the citizens with the Game, the Stakeholder Dialogue Workshop (SDW) will be implemented. The aim of the SDW is to synthesize the evidence streams from the ClairCity process such as the Delphi, Mutual Learning Workshop and Game to allow city/region stakeholders to generate a number of potential scenarios. This means examining the range of policy scenarios and checking that they match with the ambitions from the Delphi and are viable according to policy. Also, these activities will be publicized and diffused through social media, trying to continue to improve the awareness of the citizens on these themes.

\subsection{Twitter and Instagram statistics for the first period}

The first period of presence on social networks was during the Citizen Delphi Engagement Process described above.

In Fig. 7 the cumulated statistics for Twitter number of tweets and impressions are reported (right scale). On left scale the average impression by tweet is also reported. It's evident that a nearly constant average impressions by tweet is reported. Globally the profile has 88 followers.

In Fig. 8 the cumulated statistics for Instagram number of photos (right scale) and impressions are reported (left scale). Globally the profile has 178 followers.

In both cases there does not seem to be any particular effect of the content of the information on the correspondence of the public and the involvement is quite limited.

The strategy followed for the presence on Twitter and Instagram was very simple and essentially informative with little interaction with people and no or little territorial focus. The dissemination of profiles is essentially limited to the presence on other sites and traditional media (press releases, posts, direct contacts, ...).

\subsection{The presence on Facebook groups as a key element}

Completely different is the situation for the Facebook campaign on which a much more aggressive attitude has been followed.

While presence on Twitter and Instagram was based on passive posting on profile, presence on Facebook was more aggressive and finalized to stimulated participation and discussion about air pollution on the specific territory and measures on energy and traffic to have a better air quality. 


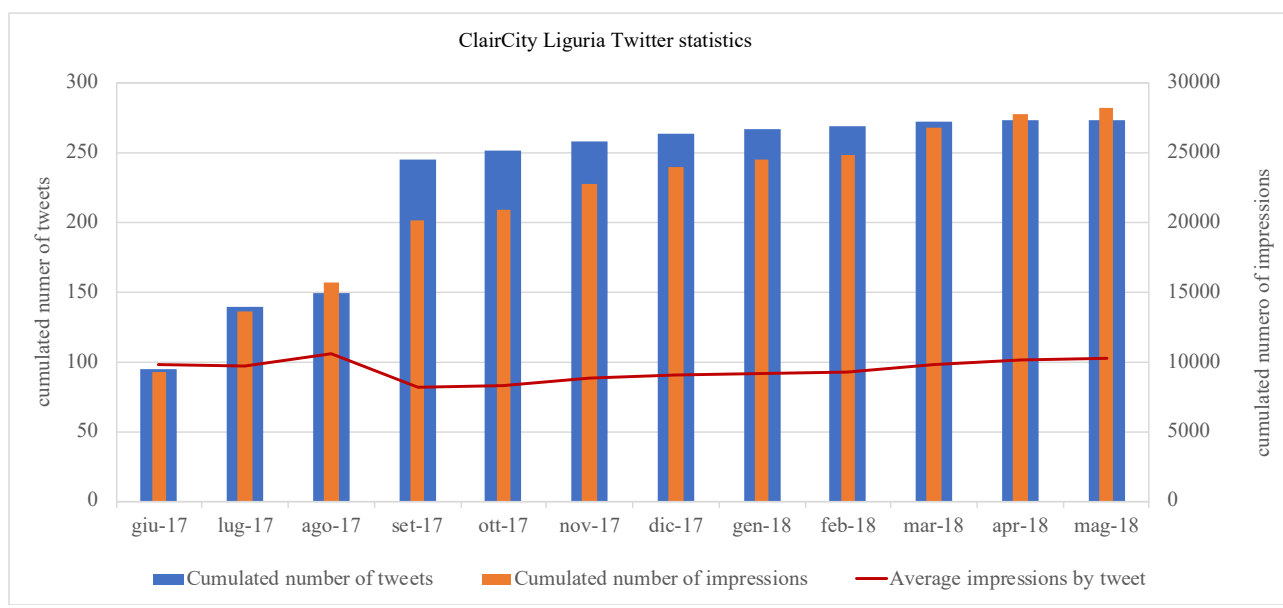

Figure 7: ClairCity Liguria Twitter statistics.

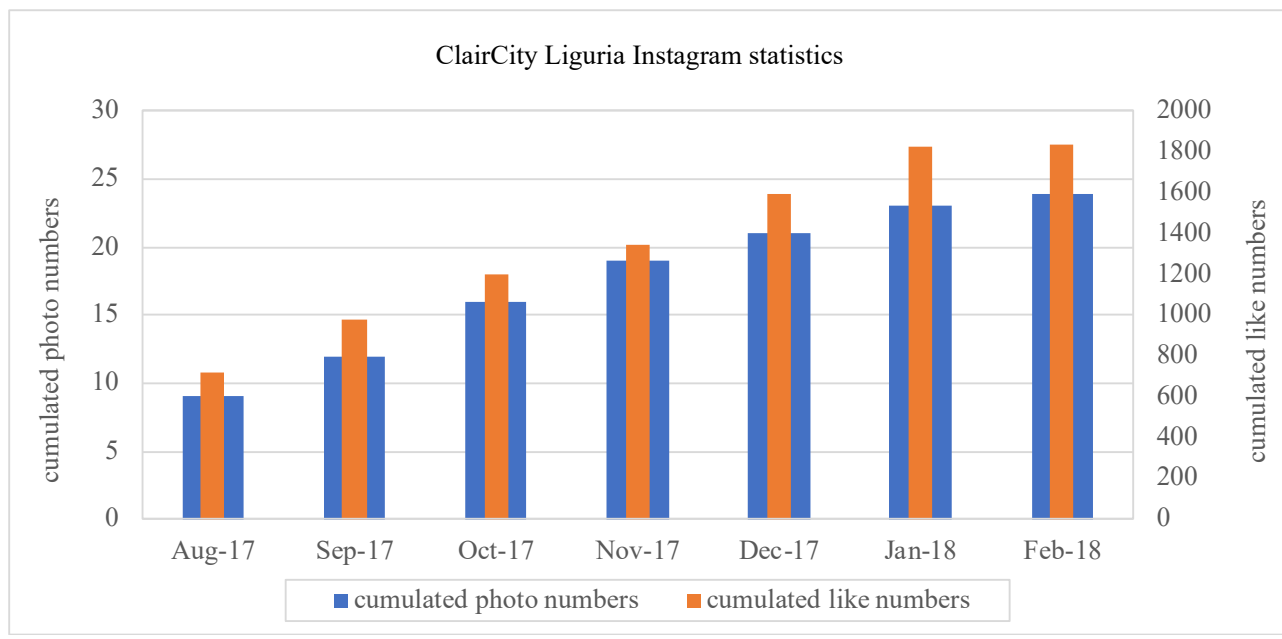

Figure 8: ClairCity Liguria Instagram statistics.

The planning of campaign on Facebook had a short initial period, similar to the presence on other networks, and consistent with the traditional use of social networks to disseminate the initiatives and events of the project.

After this phase a second phase was followed principally based on presence on Facebook groups. Facebook defines the groups as follows: "Groups provide a space to communicate about shared interests with certain people. You can create a group for anything - your family reunion, your after-work sports team, your book club - and customize the group's privacy settings depending on who you want to be able to join and see the group" [16].

A first screening was performed evaluating the groups that had an environmental, and more generally social, background. It is clear that these groups are those that potentially contain people who may be more sensitive to the ClairCity's environmental issues. 
However, these groups are generally at national level and few groups deal with the environment at a regional or municipal level. These groups are usually with limited participation and made up of people already sensitive to environmental issues, while the goal of ClairCity is to involve as many citizens as possible. Furthermore, it is necessary to make another very important consideration for the objectives of the project, which, as mentioned in the introduction, are those of change the way our societies and cities operate and function. So, all the activities of public involvement must target ordinary people in order to influence how people choose to live and interact within their city environment.

We globally joined 56 groups distributed as in the following Fig. 7.

The main characteristics of the campaign is:

- the frequency of posts is low (usually no more than 1 for week);

- $\quad$ each post has a Genoa event photo or a design from the project;

- $\quad$ each post is concise (max a few lines) and refers to the ClairCity website for further documentation;

- most of the posts raise problems on which the opinion of citizens is asked (for example on how citizens move in the city or how they heat their homes);

- some posts raise topics related to mobility much discussed by citizens (for example concerning the "sopraelevata": elevated road in central area of Genoa);

- $\quad$ some informative posts are used for main event;

- $\quad$ each post is shared in the groups.

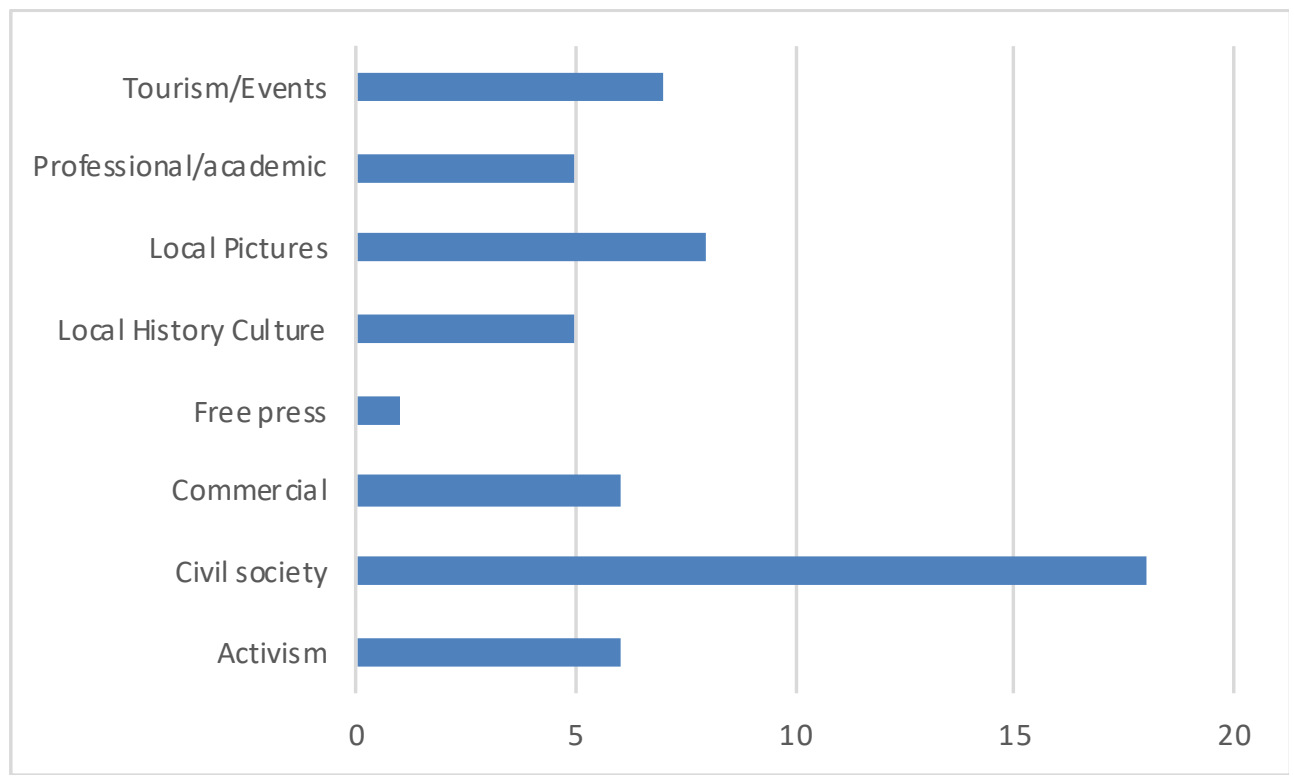

Figure 9: ClairCity Liguria Facebook groups joined by category. 


\subsection{Facebook statistics for the first period}

Globally, the Facebook page has about 300 likes that come for 95\% from Italy and in particular for $70 \%$ from the city of Genoa and $7 \%$ from the rest of the Liguria region. The distributions of likes between sex (F \& $\mathrm{M}$ in the picture) and age class is reported in Fig. 10. In Fig. 11 are reported the cumulate reach and impressions by month. The reach is the number of people for whom any content from the page or about the page entered their screen. This includes posts, check-ins, ads, social information from people who interact with the page and more (unique users).

The impressions are the number of times that any content from the page or about the page entered a person's screen. This includes posts, check-ins, ads, social information from people who interact with the page and more (total count).

The graph shows a very large participation of Facebook users, beyond any initial forecast.

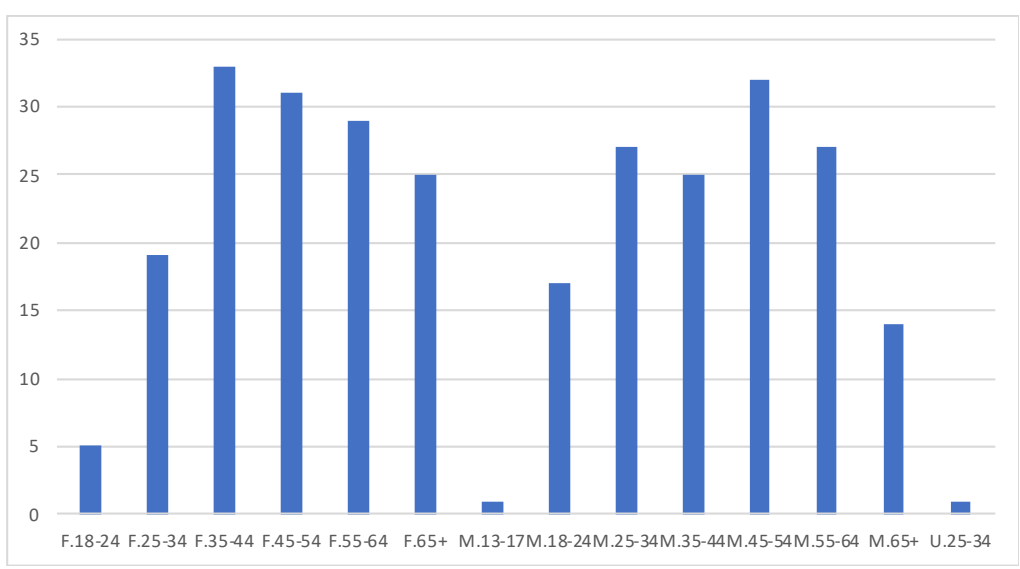

Figure 10: ClairCity Liguria Facebook likes by sex and age.

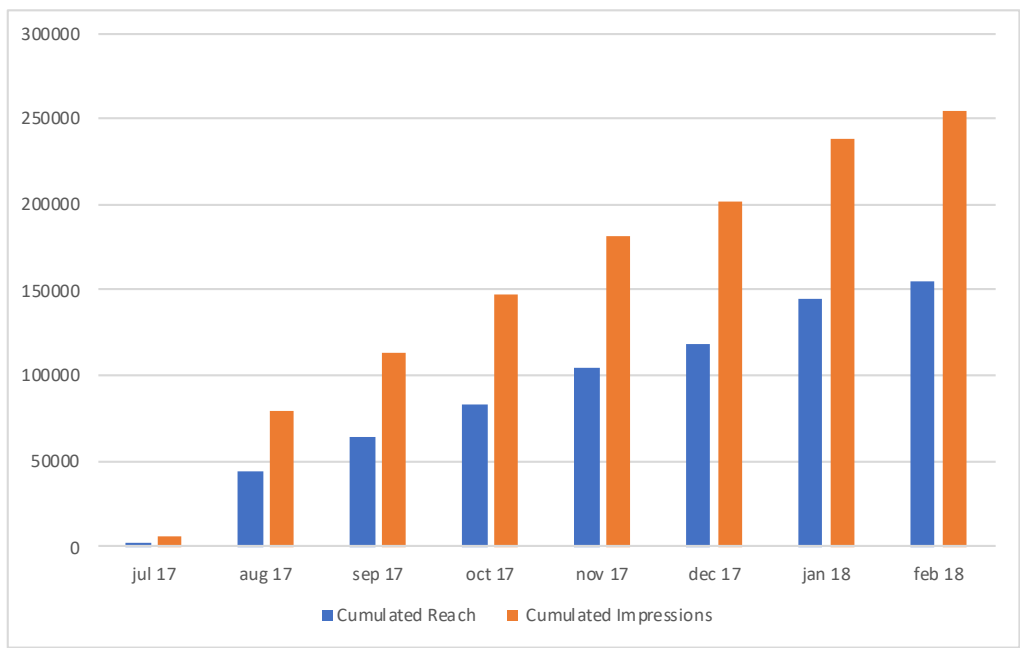

Figure 11: ClairCity Liguria Facebook reach and impressions by month. 


\section{CONCLUSIONS}

The project starts from the consideration that city citizens' behaviour and day-to-day activities are crucial element to modify to obtain the goal of reduce air pollution.

To promote ClairCity across a broad range of residents in each partner city and beyond, a suite of social media tools are running. Particular attention is devoted to the use of local Facebook groups to disseminate the information.

Analytic instruments are used to evaluate the penetration of the information between the local population while results on direct participation of citizens to surveys and meetings are used to evaluate the follow up of the social media actions.

The conclusion is that, while a traditional use of social networks is useful to spread the results of the project between the scientific community and the technicians involved in the work, the population is hardly made aware. To increase awareness, it is necessary to bring communication where the population is most easily reachable. To this end, an activity aimed at Facebook groups that are of local interest and are directly managed by citizens is an important tool for spreading project ideas and involving non-professional people.

Finally, for the purposes of assessing effective behaviour changes of the citizens behaviour induced by the project with social network activities, more objective measures must be introduced in the future with the evaluation of the effective reductions of the pressure on air quality (air pollutant emissions) induced by the project.

\section{ACKNOWLEDGEMENT}

The study was carried out in the frame of ClairCity project. The project has received funding from the European Union's Horizon 2020 research and innovation programme under grant agreement No 689289.

\section{REFERENCES}

[1] European Commission, ClairCity, Community Research and Development Information Service (CORDIS) Web Site. https://cordis.europa.eu/ project/rcn/202636_en.html. Accessed on: 19 May 2018.

[2] European Commission, Horizon 2020 - The Framework Programme for Research and Innovation, COM/2011/0808 final.

[3] ClairCity Technical Summary, 2016.

[4] Fogg Rogers, L. \& Boushel, C., ClairCity social media and online presence. ClairCity Project Deliverable D2.3, July 2016.

[5] Skoric, M.M., Qinfeng, Z.Q., Goh, D. \& San Pang, N.L., Social media and citizen engagement: A meta-analytic review. New Media \& Society, 18(9), 2015.

[6] Näkki, P. et al., Social media for citizen participation. Report on the Somus Project, VTT Technical Research Centre of Finland, 2011.

[7] Zhang, N. \& Skoric, M.M., Media use and environmental engagement: examining differential gains from news media and social media. International Journal of Communication, 12, pp. 380-403, 2018.

[8] Barnes, M.L. \& Kolt, L.J., Social networks and environmental outcomes. Proceedings of the National Academy of Sciences, 113(23), 2016.

[9] Mooney, P., Winstanley, A.C. \& Corcoran, P., Evaluating Twitter for use in environmental awareness campaigns. Proceedings of the China-Ireland Information and Communications Technologies Conference CIICT 2009, pp. 83-86, 2009.

[10] Hamid, S., Taha Ijab, M., Sulaiman, H., Anwar, R.M. \& Norman, A.A., Social media for environmental sustainability awareness in higher education. Int. Journ. of Sustain. in Higher Educ., 18(4), pp. 474-491, 2017. 
[11] Robelia, B.A., Greenhow, C. \& Burton, L., Environmental learning in online social networks: adopting environmentally responsible behaviors. Environmental Education Research, 17(4), pp. 553-575, 2011.

[12] Lyndhurst, B., The diffusion of environmental behaviours: The role of influential individuals in social networks. http://www.brooklyndhurst.co.uk/the-diffusion-ofenvironmental-behaviours-the-role-of-influential-individuals-in-social-networks$110 /$.

[13] Fernandez, M., Piccolo, L.S.G., Maynard, D., Wippoo, M., Meili, C. \& Alani, H., Talking Climate Change via Social Media: Communication, Engagement and Behaviour, Open Research Online. http://oro.open.ac.uk/46530/1/Fernandez WebSci 2016_v9.pdf.

[14] Kormos, C. \& Gifford, R., The validity of self-report measures of pro-environmental behavior: A meta-analytic review. Journal of Environmental Psychology, 40, pp. 359$337,2014$.

[15] GlobalWebIndex's flagship report on the latest trends in social media, 2018. https://cdn2.hubspot.net/hubfs/304927/Downloads/Social\%20Summary\%20Report\% 20NEW.pdf?t=1533905238694.

[16] Facebook, About groups. https://www.facebook.com/help/1629740080681586/ ?helpref=hc_fnav. 